\title{
Photoperiod Effects upon Shoot Growth and Color of Bermudagrass Fertilized with Slow-release Nitrogen Sources
}

\author{
Héctor Mario Quiroga-Garza ${ }^{1}$ \\ Instituto Nacional de Investigaciones Forestales, Agrícolas y Pecuarias \\ (INIFAP), Apartado Postal 247, Torreón, Coahuila 27000, México
}

\section{Geno A. Picchioni ${ }^{2}$ \\ Dept. of Agronomy and Horticulture, New Mexico Sate University, Box 30003, MSC 3Q, Las Cruces, NM 88003}

Additional index words. Cynodon dactylon Pers. $\times$ C. transvaalensis, clipping growth, thatch, growth periodicity

\begin{abstract}
Total plant biomass, shoot growth rate, and the periodicity in shoot growth and color of hybrid bermudagrass [Cynodon dactylon (L.) Pers. $x$ C. transvaalensis Burtt-Davy 'Tifgreen'] in response to slow-release fertilizer $\mathrm{N}$ sources, rates, and application frequencies were studied in two, 120-day greenhouse studies. Plugs were planted in plastic cylinders filled with a growing medium of 93 sand : 7 peat moss $(w / w)$. The first experiment was completed under progressively increasing photoperiod (13.1 to 14.9 hours) typical of the long-day requirements for bermudagrass growth. The second experiment occurred under progressively decreasing photoperiod (13.7 to 10.7 hours) representative of autumnal growing conditions and declining growth and $\mathrm{N}$ demand. Urea (URE), sulfur-coated urea (SCU), and hydroform (HYD, methylene urea polymers) were broadcast at $\mathrm{N}$ rates of 100 or $200 \mathrm{~kg} \cdot \mathrm{ha}^{-1}$ and at frequencies of 20 or 40 days. Bermudagrass was clipped at 3-day intervals and the average daily clipping growth rate (increase in shoot dry matter; DM) reached a maximum of $11.5 \mathrm{~g} \cdot \mathrm{m}^{-2}$ per day. Use of the least soluble source, HYD, produced the lowest total clipping DM, and at low HYD rate and frequency, leaf color intensity was frequently below the accepted standard of 7 , in the scale from 1 "tan" to 9 "dark green". A greater responsiveness of bermudagrass to $\mathbf{N}$ rate and application frequency (increased clipping growth rate and color intensification upon $\mathbf{N}$ application) occurred under increasing photoperiodic conditions as compared to decreasing photoperiodic conditions. Both clipping growth and color changed cyclically through time and mainly under long-day photoperiod ( $>12$ hours), with greater oscillation at longer fertilization interval (40 days). With either SCU or URE, at low $N$ rate and frequency (total $N$ application of $0.25 \mathrm{~g} \cdot \mathrm{m}^{-2}$ per day), clipping growth rates were above $4 \mathrm{~g} \cdot \mathrm{m}^{-2}$ per day, and turf color was at or above the minimum quality standard through most of the growing period. Higher total SCU and URE application rates, previously shown to increase $\mathrm{N}$ leaching losses in these experimental conditions, produced significantly more clipping growth and did not appear to intensify color sufficient to warrant the increased risk of $\mathrm{N}$ loss.
\end{abstract}

Intensive ntrogen $(\mathrm{N})$ fertilizer management in turfgrass cultivation has been implicated as a potential nonpoint source of groundwater $\mathrm{N}$ contamination (Exner et al., 1991; Hattori, 1999; Morey, 2000; Morris and Devitt, 2000; Petrovic, 1990). Numerous studies have concluded that the use of slowrelease $\mathrm{N}$ sources can significantly minimize the potential environmental impact of cool-

Received for publication 25 Feb. 2002. Accepted for publication 5 Mar. 2003. This work was supported by the New Mexico Agricultural Experimen Station, Consejo Nacional de Ciencia y Tecnología (CONACYT, México), and Instituto Nacional de Investigaciones Forestales, Agrícolas, y Pecuarias (INIFAP, México). Appreciation is extended to B Leinauer and W.C. Lindemann, for providing helpful comments during preparation of this manuscript. ${ }^{1}$ Director Regional de Investigación Norte-Centro, INIFAP.

${ }^{2}$ Associate Professor seasoon turfgrass $\mathrm{N}$ fertilization (Brown et al., 1982; Hummel and Waddington, 1981; Mancino and Troll, 1990; Nelson et al., 1980). However, the necessity for intensive $\mathrm{N}$ fertilization to maintain adequate turfgrass color, an important quality attribute, imposes a management-related "trade-off" arising from increased manitenance costs in mowing. Thus, turfgrass management strategy must be integrated to balance the objectives of optimizing turfgrass $\mathrm{N}$ utilization efficiency and minimizing N losses, maintaining high turfgrass quality, and moderating shoot growth.

Turfgrass-related research on the effect of slow-release $\mathrm{N}$ sources has been confined largely to cool-season species (QuirogaGarza et al., 2001). There is a pressing need to quantitatively address the influence of slow-release N sources on warm-season turfgrasses, particularly bermudagrass (Trenholm et al., 1998). Population growth rate in much of the southern United States, where bermu- dagrass is often cultivated, is relatively high compared to the national average. Because of increased urbanization, population growth in the semiarid regions of New Mexico, West Texas, and Arizona, is increasing at two to three times the rate of the national average (U.S. Census Bureau, 2002). Bermudagrass is the major warm-season turfgrass species cultivated in the growing desert cities (Picchioni and Quiroga-Garza, 1999a), and increased population growth has led to parallel increase in demand for intensively managed bermudagrass plantings. Maintenance of high quality turfgrass may require $\mathrm{N}$ applications of up to $800 \mathrm{~kg} \cdot \mathrm{ha}^{-1}$ per year (Hardt et al., 1993). In addition, turfgrass production in this semiarid region is largely dependent on irrigation, thus increasing the risk of $\mathrm{N}$ losses from the soil-turfgrass system (Picchioni and QuirogaGarza, 1999b). The use of reactive layer coating fertilizers can prevent $\mathrm{N}$ loss through leaching (Peacock and DiPaola, 1992).

We have assessed $\mathrm{N}$ uptake and leaching losses of 'Tifgreen' hybrid bermudagrass receiving different $\mathrm{N}$ sources varying in their solubility (Quiroga-Garza et al., 2001). Results corroborated with findings obtained from the aforementioned studies on cool-season turfgrasses in that leaching losses were regulated by the degree of solubility of $\mathrm{N}$ source at equivalent $\mathrm{N}$ application rates, $\mathrm{N}$ application frequencies, and environmental conditions. Data also revealed a time-related cyclical pattern of $\mathrm{N}$ uptake and utilization, and the degree of oscillation depended on $\mathrm{N}$ source solubility, application frequency, and season of year.

In this paper, we discuss the influences of photoperiod, slow-release $\mathrm{N}$ sources of differing solubility, $\mathrm{N}$ application rate, and $\mathrm{N}$ application frequency upon the growth and color of 'Tifgreen' bermudagrass throughout a 120 -d growing period.

\section{Materials and Methods}

Environmental conditions and test material. Two greenhouse experiments were conducted, each of 120-d duration, from 27 Jan. to 29 May, 1997 (Expt. 1), and from 23 July to 19 Nov., 1997 (Expt. 2) at the Fabian Garcia Plant Sciences Center of New Mexico State Univ. During the first half of Expt. 1, the $93 \mathrm{~m}^{2}$ greenhouse was heated with two gas unit heaters and artificial light was added from high-pressure sodium lamps in order to extend the natural photoperiod. During Expt. 1, total photoperiod increased progressively from 13.1 to $14.9 \mathrm{~h}$ (Table 1 ). A conventional pad/fan cooling system was used during Expt. 2, which was conducted under only natural light and a progressively decreasing photoperiod from 13.7 to $10.7 \mathrm{~h}$ (Table 1 ). Irradiance at plant level was measured using a quantum sensor (LI-89, LI-COR, Lincoln, Nebr.), and ranged from 250 to $300 \mu \mathrm{mol} \cdot \mathrm{m}^{-2} \cdot \mathrm{s}^{-1}$ (artificial light) and from 550 to $1200 \mu \mathrm{mol} \cdot \mathrm{m}^{-2} \cdot \mathrm{s}^{-1}$ (natural light). Hereafter, Expts. 1 and 2 are referred to as increasing or decreasing photoperiodic conditions, or long-day and short-day conditions, respectively. 
Table 1. Greenhouse air temperature and photoperiod conditions during the experiments

\begin{tabular}{|c|c|c|c|c|c|c|}
\hline \multirow[b]{2}{*}{ Expt. } & \multirow{2}{*}{$\begin{array}{c}\text { Period } \\
\text { of growth }\end{array}$} & \multirow{2}{*}{$\begin{array}{c}\text { Dates } \\
\text { month/day }\end{array}$} & \multicolumn{2}{|c|}{ Avg photoperiod (h) } & \multicolumn{2}{|c|}{ Temp range $\left({ }^{\circ} \mathrm{C}\right)$} \\
\hline & & & Natural & Total & Minimum & Maximum \\
\hline \multirow[t]{6}{*}{$\overline{1^{z}}$} & $1^{\mathrm{y}}$ & $1 / 27-2 / 15$ & 10.8 & 13.1 & $16.7-20.0$ & $28.6-42.0$ \\
\hline & $2^{y}$ & $2 / 16-3 / 8$ & 11.4 & 13.4 & $15.0-22.0$ & $22.0-42.0$ \\
\hline & $3^{y}$ & $3 / 9-3 / 28$ & 12.1 & 14.0 & $18.0-21.7$ & $28.3-41.0$ \\
\hline & 4 & $3 / 29-4 / 16$ & 12.7 & 14.2 & $14.1-18.2$ & $28.0-33.9$ \\
\hline & 5 & $4 / 17-5 / 6$ & 13.3 & 14.6 & $12.1-20.8$ & $26.8-37.8$ \\
\hline & 6 & $5 / 7-5 / 29$ & 13.9 & 14.9 & $15.5-18.8$ & $30.0-35.0$ \\
\hline \multirow[t]{6}{*}{$2^{x}$} & 1 & $7 / 23-8 / 11$ & 13.7 & 13.7 & $19.2-23.6$ & $31.3-37.4$ \\
\hline & 2 & $8 / 12-8 / 31$ & 13.2 & 13.2 & $18.2-23.2$ & $32.7-37.2$ \\
\hline & 3 & $9 / 1-9 / 20$ & 12.5 & 12.5 & $19.3-22.7$ & $30.5-33.5$ \\
\hline & 4 & $9 / 21-10 / 10$ & 11.8 & 11.8 & $14.4-20.5$ & $27.1-30.3$ \\
\hline & 5 & $10 / 11-10 / 30$ & 11.2 & 11.2 & $7.9-20.3$ & $25.6-29.8$ \\
\hline & 6 & $10 / 31-11 / 19$ & 10.7 & 10.7 & $9.1-14.3$ & $18.2-30.9$ \\
\hline
\end{tabular}

${ }^{\mathrm{z}}$ Artificial light supplementation from 16:30 to $20: 00 \mathrm{HR}, 250$ to $300 \mu \mathrm{mol} \cdot \mathrm{m}^{-2} \cdot \mathrm{s}^{-1}$ (Expt 1 only).

${ }^{y}$ Gas heater system.

${ }^{x} \mathrm{Pad} /$ fan cooling system.

For both experiments, 'Tifgreen'bermudagrass plugs were prepared for culture as previously described (Quiroga-Garza et al., 2001). Plugs were placed on top of a growing medium consisting of a $3.8 \mathrm{~kg}$ mixture of builder's grade 93 sand : 7 peat moss (w/w) in PVC cylinders (pots) measuring $15 \mathrm{~cm}$ in diameter and $30 \mathrm{~cm}$ in depth. While this growing medium closely resembles that used for turf planting on sandy rootzones, it only approximates field conditions. Our primary objective, however, was to use this system to evaluate relative effects of $\mathrm{N}$ rates, sources, and photoperiodic conditions ongrowth, color, and $\mathrm{N}$ use efficiency. Plugs were planted 12 Jan. for Expt. 1 or 8 July for Expt. 2, irrigated with tap water, and cut with scissors every $5 \mathrm{~d}$ at a height of $1.5 \mathrm{~cm}$ from the thatch layer until the beginning of $\mathrm{N}$ fertilization treatments (27 Jan. for Expt. 1, 23 July for Expt. 2). Pot bottoms were sealed with a plexiglass plate (cover) with a 1 -cm-diameter hole for drainage in the center of each cover. The bottom $2.5 \mathrm{~cm}$ of each pot was filled with coarse gravel, and the remaining space was filled with growing medium. Peat moss $\mathrm{N}$ concentration was $7.8 \mathrm{~g} \cdot \mathrm{kg}^{-1}$ dry weight measured as total Kjeldahl N (Bremner, 1996).

Treatment and sampling procedures. Deionized water was used for irrigation and applied every other day. A total of 6.0 and $5.6 \mathrm{~L} \mathrm{(342}$ and $319 \mathrm{~mm}$ equivalent depth of water) per pot were applied for Expts. 1 and 2 , respectively. Leaching fraction averaged $5.3 \%$ for Expt. 1 and 9.1\% for Expt. 2. Three slow-release $\mathrm{N}$ sources were evaluated: 1 ) urea (URE), total $\mathrm{N}$ of $460 \mathrm{~g} \cdot \mathrm{kg}^{-1}$ dry weight; 2) sulfur-coated urea (SCU), total N of $390 \mathrm{~g} \cdot \mathrm{kg}^{-1}$ and $\mathrm{S}$ of $120 \mathrm{~g} \cdot \mathrm{kg}^{-1}$ (N solubilization rate of $30 \%$ to $40 \%$ at $7 \mathrm{~d}$ ); and 3) hydroform (HYD), total $\mathrm{N}$ of $380 \mathrm{~g} \cdot \mathrm{kg}^{-1}\left(110 \mathrm{~g} \cdot \mathrm{kg}^{-1}\right.$ as water-soluble $\mathrm{N}$ from urea, methylene diurea, and dimethylene triurea; $270 \mathrm{~g} \cdot \mathrm{kg}^{-1}$ as waterinsoluble $\mathrm{N}$ from methylene urea polymers). Fertilizer particles were standardized to use only those particles between 1 and $2 \mathrm{~mm}$. All $\mathrm{N}$ sources were broadcast at two $\mathrm{N}$ rates (100 or $200 \mathrm{~kg} \cdot \mathrm{ha}^{-1}$ ) and at two frequencies (every 20 or $40 \mathrm{~d}$ ). Treatments provided a range of total $\mathrm{N}$ application of between 300 to 1200 $\mathrm{kg} \cdot \mathrm{ha}^{-1}$ per $120 \mathrm{~d}$ (equivalent to 0.25 to 1.0 $\mathrm{g} \cdot \mathrm{m}^{-2}$ per day). A supplemental nutrient solution (without $\mathrm{N}$ ) was applied at $20 \mathrm{~mL}$ per pot every $20 \mathrm{~d}$. This solution included the following rates for macronutrients $\left(\mathrm{g} \cdot \mathrm{m}^{-2}\right.$ per day): K (0.81), P (0.64), S (0.26), Ca (0.23), and $\mathrm{Mg}(0.19)$, plus a complete micronutrient supplementation as described by Turner and Hummel (1992).

Clippings (fresh shoot biomass) were cut with scissors at 3 -d intervals at a cutting height of $1.5 \mathrm{~cm}$, dried at $60^{\circ} \mathrm{C}$ for $48 \mathrm{~h}$, weighed, and ground to pass a $40-\mathrm{mesh}(0.425-\mathrm{mm})$ screen. Clipping growth rate (CliGR) was expressed as dry matter $(D M)$ in $g \cdot \mathrm{m}^{-2}$ per day. At the end of each experiment, the plugs were washed and separated into verdure and thatch plus roots. Verdure was defined as shoot material remaining after cutting, and thatch plus roots as rhizomes, stolons, roots, and nonliving plant tissues. These fractions were dried at $60{ }^{\circ} \mathrm{C}$ for $72 \mathrm{~h}$, weighed, and ground similar to the clippings. Total DM obtained at the beginning of fertilization treatments (verdure and thatch plus roots) was subtracted from final DM to obtain DM gain in verdure and thatch plus roots attributable to the treatment period. Visual, above-ground color rating was recorded prior to clipping as prescribed by Johnson et al. (1987), where $1=$ tan color and $9=$ dark green color.

Statistical design and analyses. Because of a temperature gradient inside the greenhouse, the $3 \times 2 \times 2$ factorial treatment combinations $(3 \mathrm{~N}$ sources $\times 2 \mathrm{~N}$ rates $\times 2 \mathrm{~N}$ application frequencies) were distributed in a randomized complete-block design with three replications (SAS, 1990). Three-factor analyses of variance were performed for total accumulated dry matter of clippings, verdure, and thatch plus roots following $120 \mathrm{~d} \mathrm{~N}$ fertilization. Main effect means for $\mathrm{N}$ source, rate, and frequency were separated by Tukey's test $(P \leq 0.05)$. Periodic clipping DM accumulation, $\mathrm{CliGR}$, and color rating were assessed at 6, 20-d periods, $35,3-\mathrm{d}$ periods, and $12,10-\mathrm{d}$ periods, respectively, throughout the 120 -d experiments. The periods were treated as repeated measurements and the Huynh-Feldt conditions were tested. Because the Huynh-Feldt conditions were satisfied, periodic clipping DM accumulation, CliGR, and color rating were analyzed as a split plot (SAS, 1990). The main plot was the $3 \times 2 \times 2$ factorial and the period factor was the subplot.

\section{Results and Discussion}

Total clipping DM production. Total accumulated clipping DM production (120 days) as a function of $\mathrm{N}$ source, rate, and application frequency was similar in both experiments (Table 2). As the second experiment was conducted into the autumnal months without supplemental lighting, and declining photoperiod and temperature, DM yield was lower than in Expt. 1. In both experiments, the higher $\mathrm{N}$ rate and frequency produced greater total accumulated clipping DM, and DM yield was lowest with HYD.

Clipping DM through time. When accumulated clipping DM per period was plotted through time (six periods of $20 \mathrm{~d}$ each; Fig. 1), the same general trends for main effects of $\mathrm{N}$ source, rate, and frequency were observed as those for total accumulated DM yield discussed above. A different trend occurred for each of the experiments on periods main effect. Expt. 1 was conducted under a progressively increasing photoperiod, and clipping DM production generally increased through the growing period. The drop in clipping DM production at the end of period 4 of Expt. 1 may have resulted from the relatively low nighttime minimum temperatures (Table 1). In contrast to the increasing photoperiodic conditions of Expt. 1, there was an overall decreasing trend for clipping dry matter production with time for Expt. 2, which was conducted during a progressively decreasing photoperiod.

Lower minimum temperature during periods 5 and 6 of Expt. 2 below those of periods 5 and 6 of Expt. 1 (Table 1) probably contributed to the shoot growth differential between the experiments during these two periods. However, both minimum and maximum temperatures of Expt. 2 were no less favorable to bermudagrass growth than those of Expt. 1 through period 4 (Table 1). Thus, photoperiod appears to have been the more important variable leading to the general decreasing clipping dry matter accumulation in Expt. 2, at least through period 4 .

Significant main factor interactions on the time course of clipping DM accumulation were observed in both experiments. While the 20-d application frequency with all $\mathrm{N}$ sources led to a general increase in clipping DM production through time in Expt. 1 and decrease with time in Expt. 2, the 40-d application frequency resulted in growth "surges" and "depressions" in response to $\mathrm{N}$ supply. The cyclic pattern of growth was particularly apparent in Expt. 1 (long-day conditions), with the soluble source URE at both $\mathrm{N}$ rates, and with SCU at low $\mathrm{N}$ rate. Such cyclical growth was less apparent with HYD at either rate and with SCU at the high rate of applied $\mathrm{N}$.

By the end of the second half of the 40-d period (periods 2, 4, and 6), the bermudagrass may have experienced transient $\mathrm{N}$ deficiency stress, thus resulting in sharp declinations in clipping DM production. After $\mathrm{N}$ application at the termination of periods 2 and 4 , DM production increased. This distinct periodicity in growth is synchronous with N uptake (Quiroga- 
Table 2. Main factor means for total accumulated dry matter(DM) in 'Tifgreen' bermudagrass clippings, verdure, and thatch plus roots after $120 \mathrm{~d}$, with three $\mathrm{N}$ sources, two N rates, and two $\mathrm{N}$ fertilization frequencies. Each value represents the average of three observations.

\begin{tabular}{|c|c|c|c|c|c|c|c|}
\hline \multirow{2}{*}{ Variable } & & \multicolumn{2}{|c|}{$\begin{array}{c}\text { Total clipping } \\
\text { DM }\end{array}$} & \multicolumn{2}{|c|}{$\begin{array}{l}\text { Verdure } \\
\text { DM }\end{array}$} & \multicolumn{2}{|c|}{$\begin{array}{c}\text { Thatch + roots } \\
\text { DM }\end{array}$} \\
\hline & & Expt. 1 & $\overline{\text { Expt. } 2}$ & Expt. 1 & $\overline{\text { Expt. } 2}$ & Expt. & $\overline{\text { Expt. } 2}$ \\
\hline & & ---- & $-\cdots$ & ------ & $\left.\mathrm{g} \cdot \mathrm{m}^{-2}\right)$ & - & -- \\
\hline \multirow[t]{3}{*}{ N Source ${ }^{z}$} & HYD & $477 b^{y}$ & $402 \mathrm{~b}$ & $399 \mathrm{a}$ & $309 a$ & $1605 \mathrm{a}$ & $1745 \mathrm{a}$ \\
\hline & URE & $673 \mathrm{a}$ & $588 \mathrm{a}$ & $435 \mathrm{a}$ & $317 \mathrm{a}$ & $1681 \mathrm{a}$ & $1745 \mathrm{a}$ \\
\hline & SCU & $714 \mathrm{a}$ & $604 \mathrm{a}$ & $411 \mathrm{a}$ & $306 \mathrm{a}$ & $1529 a$ & $1572 \mathrm{a}$ \\
\hline N Rate & 100 & $526 \mathrm{~b}$ & $476 \mathrm{~b}$ & $409 \mathrm{a}$ & $306 \mathrm{a}$ & $1597 \mathrm{a}$ & $1696 \mathrm{a}$ \\
\hline$\left(\mathrm{kg} \cdot \mathrm{ha}^{-1}\right)$ & 200 & $718 \mathrm{a}$ & $586 \mathrm{a}$ & $421 \mathrm{a}$ & $315 \mathrm{a}$ & $1613 \mathrm{a}$ & 1678 a \\
\hline N Frequency & 20 & $739 \mathrm{a}$ & $600 \mathrm{a}$ & $428 \mathrm{a}$ & $296 \mathrm{a}$ & $1668 \mathrm{a}$ & $1743 \mathrm{a}$ \\
\hline (d) & 40 & $505 \mathrm{~b}$ & $463 \mathrm{~b}$ & $402 \mathrm{a}$ & $325 \mathrm{a}$ & $1542 \mathrm{a}$ & $1632 \mathrm{a}$ \\
\hline
\end{tabular}

${ }^{\mathrm{z}}$ Hydroform (HYD), urea (URE), and sulfur-coated urea (SCU).

${ }^{\mathrm{y}}$ Mean separation in columns within $\mathrm{N}$ source, rate, or frequency by Tukey's test $(P \leq 0.05)$

Garza et al., 2001), and may be related to a temporal increase in plant $\mathrm{N}$ demand associated with $\mathrm{N}$-limiting conditions, as previously suggested in cool-season turfgrasses (Bowman et al., 1989). In that study, N-deficient ryegrass (Lolium perenne L.) and Kentucky bluegrass (Poa pratensis L.) increased their maximal rate of $\mathrm{N}$ uptake (Imax) by 6-fold when a deficient level of soil $\mathrm{N}$ was re-established to a sufficient $\mathrm{N}$ concentration. The increment in Imax in N-deficient plants has also been reported in maize (Hole et al., 1990), and supports the hypothesis that a recycling pool of organic $\mathrm{N}$ exists in plants to regulate $\mathrm{N}\left(\mathrm{NO}_{3}\right)$ uptake (Imsande and Touraine, 1994; Cooper and Clarkson, 1989).

The generally low clipping DM production with HYD, particularly at low $\mathrm{N}$ rate, was related to the low $\mathrm{N}$ solubility rate and $\mathrm{N}$ availability of this source (Table 2; Fig. 1; Turner and Hummel, 1992). Visual (qualitative) assessment supports the latter observation, since in both experiments, there was relatively poor stand density with HYD at the infrequent and low $\mathrm{N}$ application rate. However, at the high $\mathrm{N}$ rate, growth with HYD tended to be more similar to that of the other $\mathrm{N}$ sources with the more frequent fertilization. Thus, the higher $\mathrm{N}$ rate combined with increased fertilization frequency overcame the slow HYD-N dissolu- tion rate. In addition, at low $\mathrm{N}$ application rate and frequency, clipping DM gains differed less noticeably between the $\mathrm{N}$ sources, when the grass had experienced a longer duration without added $\mathrm{N}$ (periods 2, 4, and 6). Further, during Expt. 2, although clipping DM was least with HYD following the first fertilization (period 1 ), by the end of the experiment (periods 5 and 6), there were no observable differences in clipping growth between the $\mathrm{N}$ sources within a given rate, probably because the decreasing photoperiod and temperature reduced bermudagrass growth, thus eliminating the effects of the $\mathrm{N}$ sources. Therefore, slowly soluble $\mathrm{N}$ sources (e.g., HYD) may result in similar bermudagrass responsiveness as more rapidly soluble $\mathrm{N}$ sources while minimizing the $\mathrm{N}$ losses we observed earlier (Quiroga-Garza et al., 2001), depending on the $\mathrm{N}$ rate, application frequency, and season.

Expt. 2 progressed into autumn with a gradually decreasing photoperiod and temperature. At high fertilization frequency, clipping dry matter accumulation had stabilized up to the third period (Fig. 1). By contrast, at low fertilization frequency, growth was highly cyclical up to the fourth period. Subsequent to the fourth period and irrespective of the fertilization frequency, the differences between high and low $\mathrm{N}$ rate and $\mathrm{N}$ source, and the fluctuating pattern in clipping growth had diminished, presumably because the onset of dormancy limits $\mathrm{N}$ demand and the capacity of bermudagrass to

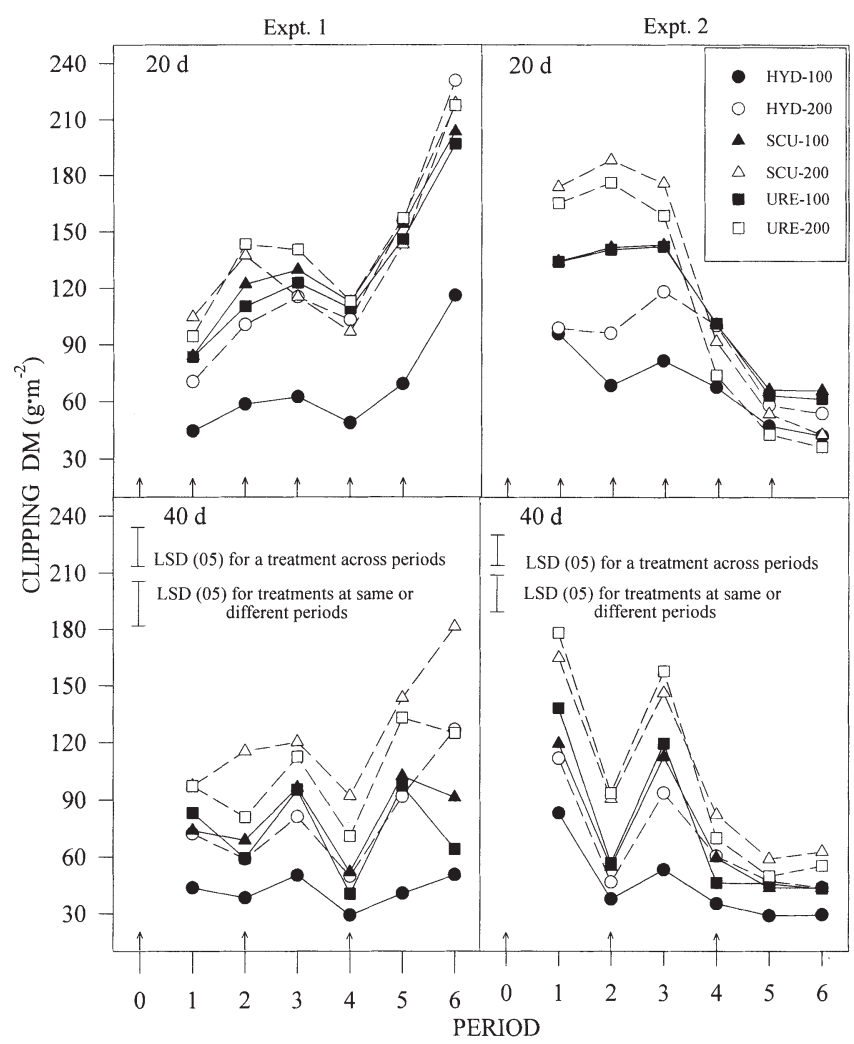

Fig. 1. Clipping DM yield per period ( $20 \mathrm{~d}$ each) in 'Tifgreen' bermudagrass with three $\mathrm{N}$ sources (Hydroform, HYD; sulfur-coated urea, $\mathrm{SCU}$; and urea, URE), two $\mathrm{N}$ rates ( 100 and $200 \mathrm{~kg} \cdot \mathrm{ha}^{-1}$ ), and two fertilization frequencies (every 20 and $40 \mathrm{~d}$ ). Each point represents the average of three observations. Vertical bars represent $\mathrm{LSD}_{05}$ for comparisons among treatments ofeach experiment. Arrows represent time of $\mathrm{N}$ application.

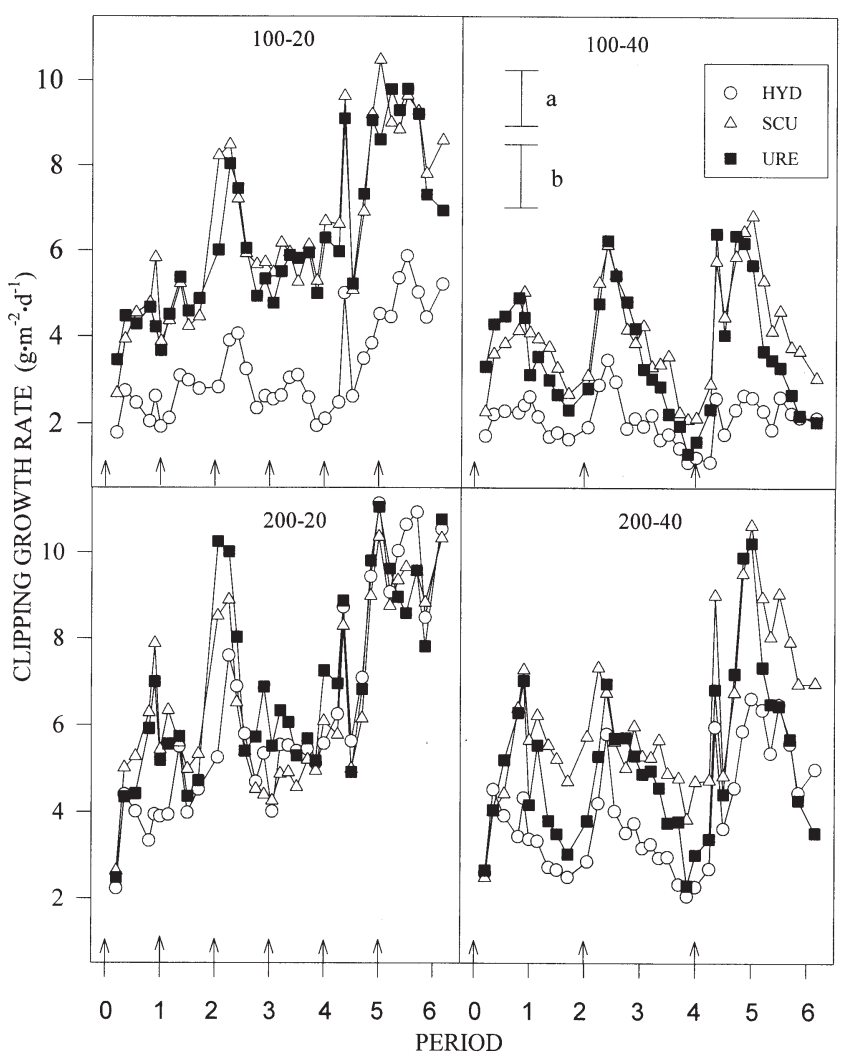

Fig. 2. Clipping growth rate, Expt. 1, of 'Tifgreen' bermudagrass with three $\mathrm{N}$ sources (Hydroform, HYD; sulfur-coated urea, SCU; and urea, URE), two $\mathrm{N}$ rates $\left(100\right.$ and $\left.200 \mathrm{~kg} \cdot \mathrm{ha}^{-1}\right)$, and two fertilization frequencies (every 20 and $40 \mathrm{~d}$ ). Each point represents the average growth rate of three observations during a 3-d interval; periods represent $20 \mathrm{~d}$. Vertical bars represent $\mathrm{LSD}_{05}$ for treatments across sampling times (a) or treatments at the same or different sampling time (b). 
respond to $\mathrm{N}$ supply. Bermudagrass dormancy is functionally linked to the autumnal seasonal patterns of declining temperature and shortening photoperiod, characteristic of the semiarid southwestern United States. At the onset of the fall season, low night temperatures favor chlorophyll degradation, and this process is accelerated by high light intensity during the daytime (Youngner, 1959). Photoperiod $<12$ $\mathrm{h}$ significantly reduces leaf extension rate in bermudagrass (Marousky et al., 1992). The photoperiod between periods 3 and 4 (60-80 d) of Expt. 2 had decreased below this critical value (Table 1), and along with declining temperature, was associated with a marked reduction in clipping dry matter production. These data indicate that bermudagrass growing at daylengths of $12 \mathrm{~h}$ or less (with declining temperature) will not respond to $\mathrm{N}$ fertilization, regardless of rate and frequency.

Clipping growth rate (CliGR). CliGR ranged between 1.5 and $11.5 \mathrm{~g} \cdot \mathrm{m}^{-2}$ per day, depending largely on $\mathrm{N}$ source, rate, and season of application. The increase in CliGR with high Napplication rate and frequency in Expt. 1 (Fig. 2) did not always occur shortly after $\mathrm{N}$ application. However, we observed a general cyclical pattern of CliGR in response to $\mathrm{N}$ application in both Expt. 1 (Fig. 2) and Expt. 2 (Fig. 3). After a fertilization, CliGR increased for an average of 6-9 d ( 2 to 3 adjacent measurement dates), and then consistently declined with time prior to the next $\mathrm{N}$ application. The overall average CliGR and magnitude of the CliGR increase following each fertilization tended to be greater with SCU and URE than with HYD, probably because of the greater N solubility of SCU and URE. During Expt. 1 and at both $\mathrm{N}$ application frequencies, the CliGR response to $\mathrm{N}$ was lost between the third and fourth periods (60-80 d), which may have been attributable to relatively low nighttime minimum temperatures.

During Expt. 2, the cyclic pattern in CliGR was apparent up to $80 \mathrm{~d}$ after the experiment had begun (period 4), but from this time, the decreasing temperature and suboptimal growth photoperiod had limited the response to $\mathrm{N}$ fertilization. In contrast to the general increasing trend of CliGR in Expt. 1 (increasing photoperiod), there was little or no increasing trend in CliGR in Expt. 2 (decreasing photoperiod).

Verdure and thatch plus root DM. In neither experiment was there a statistically significant main factor effect or interaction ( $N$ source, rate, and frequency) on verdure and thatch plus root DM gain (Table 2). At the end of $120 \mathrm{~d}$, verdure DM averaged 415 and $311 \mathrm{~g} \cdot \mathrm{m}^{-2}$ per day, and thatch plus root DM averaged 1605 and 1687 $\mathrm{g} \cdot \mathrm{m}^{-2}$ per day for Expts. 1 and 2, respectively. The slightly greater average DM for thatch plus roots in Expt. 2 was presumably associ- ated with preferential carbohydrate allocation and accumulation in the true root and rhizome system as bermudagrass progresses into the dormancy period (White and Schmidt, 1990). Unlike our findings, however, differential $\mathrm{N}$ source solubility may affect bermudagrass root and rhizome growth under a given set of experimental conditions. For example, Horst et al. (1985) showed that bermudagrass root plus rhizome dry weight was greater in plots fertilized with urea and $\left(\mathrm{NH}_{4}\right)_{2} \mathrm{SO}_{4}$ than with the more slowly soluble methylene urea.

Color rating through time. Nitrogen source, rate, frequency, photoperiod, and temperature conditions had a marked effect on leaf color through time (Fig. 4). In both experiments, color rating was at or above the minimum acceptable level of 7 if $\mathrm{N}$ were applied on a 20-d frequency, with the exception of the final $20 \mathrm{~d}$ of Expt. 2 which had decreasing photoperiod and temperature. With 40-d N fertilization frequency, color ratings dropped below 7, especially with HYD at lower $\mathrm{N}$ rate in Expt. 1, and at both $\mathrm{N}$ rates in Expt. 2. A cyclic color change pattern was observed with each $\mathrm{N}$ source at the fertilization frequency of $40 \mathrm{~d}$. Color ratings tended to decrease from about the second half of each 40-d cycle, and this may have reflected gradual depletion of available $\mathrm{N}$. Color rating subsequently increased upon $\mathrm{N}$ application. Fertilizers with low $\mathrm{N}$ solubil-

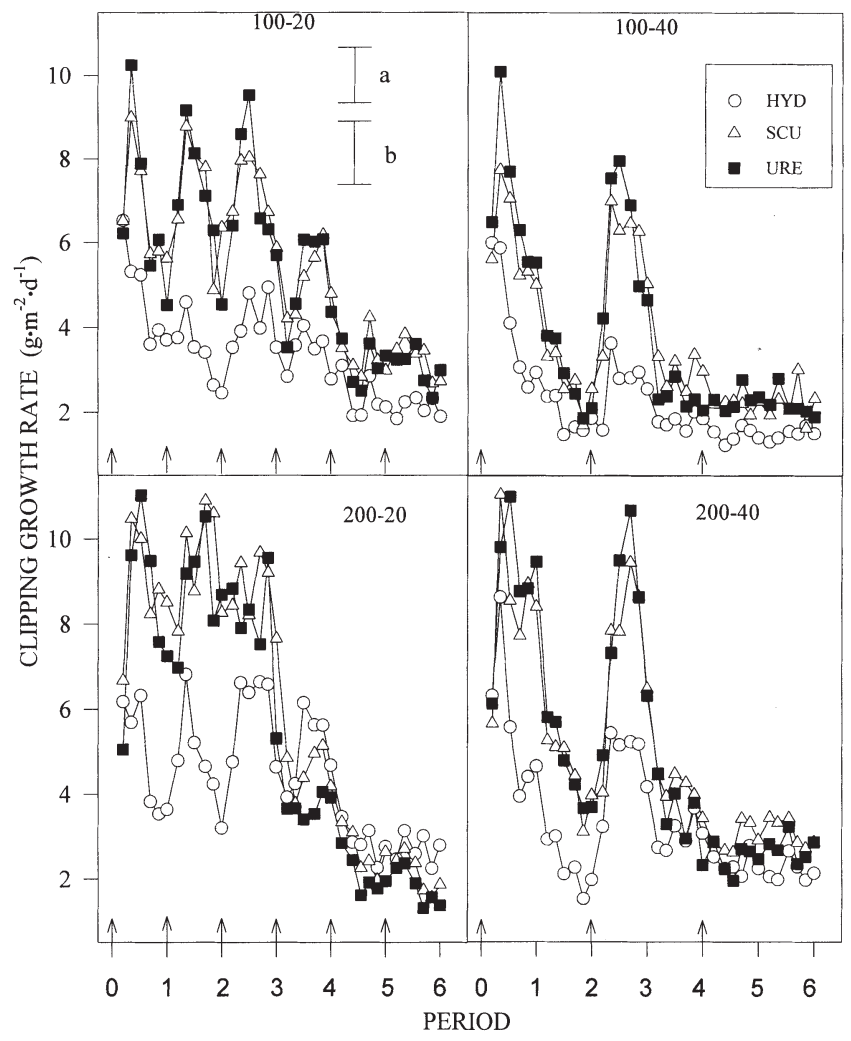

Fig. 3. Clipping growth rate, Expt. 2, of 'Tifgreen' bermudagrass with three $\mathrm{N}$ sources (Hydroform, HYD; sulfur-coated urea, SCU; and urea, URE), two $\mathrm{N}$ rates $\left(100\right.$ and $200 \mathrm{~kg} \cdot \mathrm{ha}^{-1}$ ), and two fertilization frequencies (every 20 and $40 \mathrm{~d}$ ). Each point represents the average growth rate of three observations during a 3-day interval; periods represent $20 \mathrm{~d}$. Vertical bars represent $\mathrm{LSD}_{05}$ for treatments across sampling times (a) or treatments at the same or different sampling time (b).

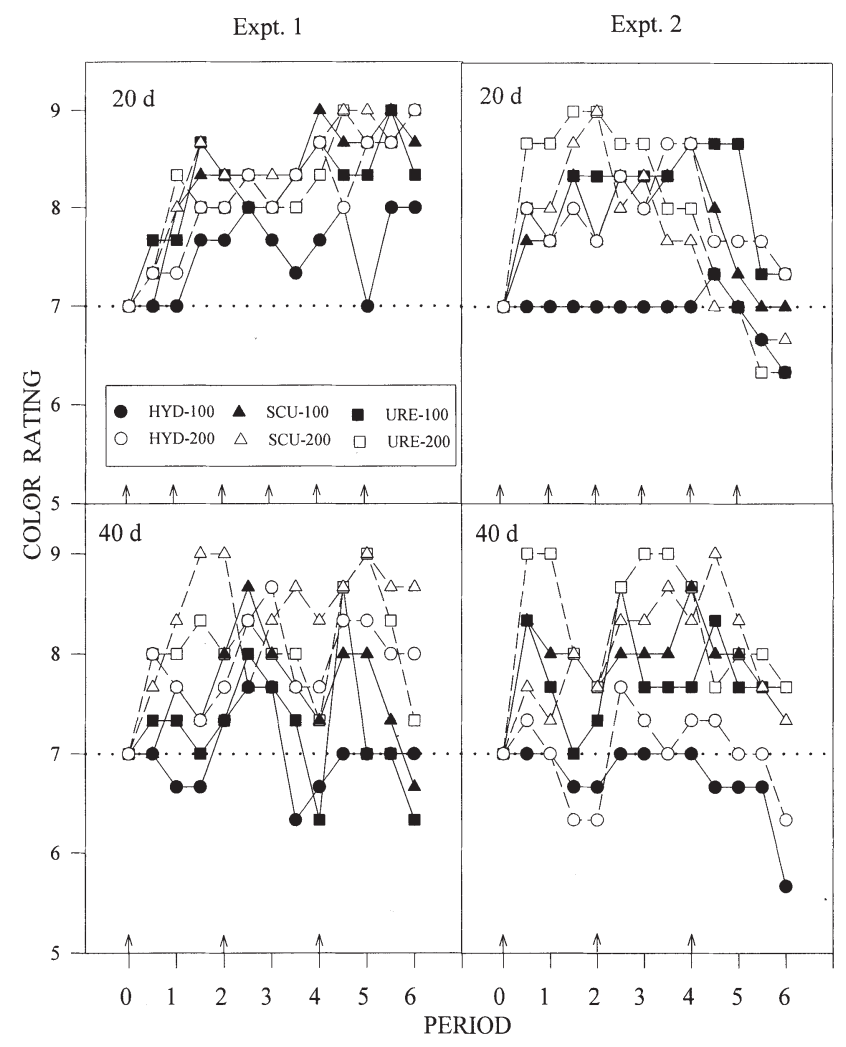

Fig. 4. Clipping color rating of 'Tifgreen' bermudagrass with three N sources (Hydroform, HYD; sulfur-coated urea, SCU; and urea, URE), two N rates $\left(100\right.$ and $200 \mathrm{~kg} \cdot \mathrm{ha}^{-1}$ ), and two fertilization frequencies (every 20 and 40 d). Each point represents the average of three observations. Vertical bars represent $\mathrm{LSD}_{05}$ for comparisons among treatments of each experiment. Arrows represent time of $\mathrm{N}$ application. Color rating: 1 (tan color) to 9 (dark green color). 
ity as HYD, may be combined with highly soluble sources as urea to maintain acceptable turf quality (Peacock and Dipaola, 1992).

As time progressed in Expt. 1 (long-day conditions), there was a general increase in color rating with the exception of the low $\mathrm{N}$ rate treatments at 40-d application frequency. At the beginning of Expt. 2, the long-day conditions $(>13 \mathrm{~h})$ promoted rapid color intensification just following the first fertilization, particularly for URE. Initial greening was less noticeable for the more sparingly soluble SCU and HYD. As Expt. 2 progressed into decreasing photoperiod and temperature $(\approx 80 \mathrm{~d}$ after the experiment started; period 4 , photoperiod $<12 \mathrm{~h}$ ), color loss had begun to occur in all treatments. Senescence-related changes, such as chlorophyll degradation and $\mathrm{N}$ redistribution from shoots to perennial storage organs, are functionally linked to declining photoperiod and temperature of autumn (Youngner, 1959). These naturally-occurring processes combined to limit bermudagrass growth and color response to $\mathrm{N}$ fertilization, despite the high $\mathrm{N}$ application rates of up to $1200 \mathrm{~kg} \cdot \mathrm{ha}^{-1}$ per $120 \mathrm{~d}$.

Increased responsiveness of hybrid bermudagrass to the more soluble URE and SCU in comparison to the slowly soluble HYD, was expected. The findings provide insight to bermudagrass $\mathrm{N}$ management strategy for maintenance of quality and vigor, moderation of top growth, and minimization of $\mathrm{N}$ loss. For example, the low application rate and frequency of URE and SCU produced clipping yields that, while cyclical, were moderated below that of higher rate and frequency, and the color generally stayed at or above the minimum standard throughout a 4-month growing period (Figs. 1 and 4). Increasing the rate and frequency of URE and SCU application increased clipping growth and did not appear to offer major improvement of color that would warrant the attendant risk of $\mathrm{NO}_{3}$ leaching loss that exists during autumnal growing periods (QuirogaGarza et al., 2001).

Use of the slowly soluble HYD did not promote as much vigor and color as did URE and SCU at equivalent $\mathrm{N}$ application rates and frequencies (Figs. 1 and 4). However, high application rate and frequency overcame the lack of HYD solubility and improved the shoot color rating throughout much of the growth periods reported in this study. The results with HYD raise particular attention to late season fall $\mathrm{N}$ fertilization of warm-season turfgrasses. Late season $\mathrm{N}$ application is a widely used and controversial practice in southern U.S. latitudes, with the aims of prolonging color retention in the fall season and of accelerating regreening the following spring season (Goatley et al., 1998). In the latter stages of Expt. 2 with high $\mathrm{N}$ application rate and frequency, stand vigor and color were hardly affected by $\mathrm{N}$ source, yet $\mathrm{NO}_{3}$ leaching losses increased greatly with increased N source solubility (Quiroga-Garza et al., 2001). Thus, slowly soluble $\mathrm{N}$ sources may be highly beneficial during the fall period, considering the importance of integrated management for turf quality maintenance, mowing and fertilization inputs, and the abatement of environmental impact of $\mathrm{N}$ fertilization.

\section{Literature Cited}

Bowman, D.C., J.L. Paul, and W.B. Davis. 1989. Nitrate and ammonium uptake by nitrogen-deficient perennial ryegrass and Kentucky bluegrass turf. J. Amer. Soc. Hort. Sci. 114:421-426.

Bremner,J.M. 1996. Nitrogen - Total, p. 1085-1121. In: D.L. Sparks (ed.). Methods of soil analysis. Part 3. Chemical methods. SSSA. Book Ser. no. 5. Madison, Wisc.

Brown, K.W., J.C. Thomas, and R.L. Duble. 1982. Nitrogen source effect on nitrate and ammonium leaching and runoff from greens. Agron. J. 74: 947-950.

Cooper, H.D. and D.T. Clarkson. 1989. Cycling of amino-nitrogen and other nutrients between shoots and roots in cereals. A possible mechanism integrating shoot and root in the regulation of nutrient uptake. J. Expt. Bot. 40:756-762.

Exner, M.E., M.E. Burbach, D.G. Watts, R.C. Sherman, and R.F. Spalding. 1991. Deep nitrate movement in the unsaturated zone of a simulated urban lawn. J. Environ. Qual. 20:658-662.

Goatley, J.M., Jr., V.L. Maddox, and K.L. Hensler. 1998. Late-season applications of various nitrogen sources affect color and carbohydrate content of 'Tiflawn' and Arizona common bermudagrass. HortScience 33:692-697.

Hardt, G., B. Leinauer, and H. Schulz. 1993. Nitrogen leaching losses of different $\mathrm{N}$-sources and N-levels from golfgreens, p. 950-957. In: R.N. Carrow, N.E. Christians, and R.C. Sherman (eds.). Intl. Turfgrass Soc. Res. J. 7. Intertec Publishing, Overland, Kans.

Hattori, K. 1999. Keeping chemicals out of our groundwater. Turf Mag. (West edition). 12(2): A5-A15.

Hole, D.J., A.M. Emran, Y. Fares, and M.C. Drew. 1990. Induction of nitrate transport in maize roots and kinetics of influx, measured with nitrogen-13. Plant Physiol. 93:642-647.

Horst, G.L., L.B. Fenn, and N.B. Dunning. 1985. Bermudagrass turf responses to nitrogen sources. J. Amer. Soc. Hort. Sci. 110:759-761.

Hummel, N.W., Jr. and D.V. Waddington. 1981. Evaluation of slow-release nitrogen sources on 'Baron' Kentucky bluegrass. Soil Sci. Soc. Amer. J. 45:966-970.

Imsande, J. and B. Touraine. 1994. Nitrogen demand and the regulation of nitrate uptake. Plant Physiol. 105:3-7.
Johnson, B.J., R.N. Carrow, and R.E. Burns. 1987. Bermudagrass turf response to mowing practices and fertilizer. Agron. J. 79:677-680.

Mancino, C.F. and J. Troll. 1990. Nitrate and ammonium leaching losses from $\mathrm{N}$ fertilizers applied to 'Penncross' creeping bentgrass. HortScience 25:194-196.

Marousky, F.J., A.E. Dudeck, L.B. McCarty, and S.F. Anderson. 1992. Influence of daylength and fertility on growth of bermudagrass cultivars. Proc. Fla. State Hort. Soc. 105:236-238.

Morey, L. 2000. The perceptions and realities of nitrate leaching. TTurf Mag. (West edition). 23(2):A5-A11.

Morris, B. and D. Devitt. 2000. Turf fertilization-More isn't better. Southwest Trees and Turf 5(3):4.

Nelson, K.E., A.J. Turgeon, and J.R. Street. 1980 Thatch influence on mobility and transformation of nitrogen carriers applied to turf. Agron. J. 72:487-492.

Peacock, C.H. and J.M. DiPaola. 1992. Bermudagrass response to reactive layer coated fertilizers. Agron. J. 84:946-950.

Petrovic, A.M. 1990. The fate of nitrogenous fertilizers applied to turfgrass. J. Environ. Qual. 19:1-14.

Picchioni, G.A. and H.M. Quiroga-Garza. 1999a. Growth and nitrogen partitioning, recovery, and losses in bermudagrass receiving soluble sources of labeled ${ }^{15}$ nitrogen. J. Amer. Soc. Hort. Sci. 124:719-725.

Picchioni, G.A. and H.M. Quiroga-Garza. 1999b. Comparison of slow-release and soluble nitrogen sources for bermudagrass: Growth, color, N recovery, and $\mathrm{N}$ losses. Proc. Southwest Turfgrass Assn., p. 45-60, Ruidoso, New Mexico.

Quiroga-Garza., H.M., G.A. Picchioni, and M.D Remmenga. 2001. Bermudagrass fertilized with slow-release nitrogen sources. I. Nitrogen uptake and potential leaching losses. J Environ. Qual. 30:440-448.

SAS Institute. 1990. SAS/STAT. User's guide. Volume 2, GLM-VARCOMP. SAS Inst., Cary, N.C.

Trenholm, L.E., A.E. Dudeck, J.B. Sartain, and J.L. Cisar. 1998. Bermudagrass growth, total nonstructural carbohydrate concentration, and quality as influenced by nitrogen and potassium. Crop Sci. 38:168-174.

Turner, T.R. and N.W. Hummel, Jr. 1992. Nutritional requirements and fertilization. p. 387-439. In: D.V. Waddington, R.N. Carrow, and R.C. Sherman (eds.). Turfgrass. Agron. Monogr. 32. ASA, CSSA, and SSSA, Madison Wisc.

U.S. Census Bureau. 2002. http://www.census.gov. 28 Sept. 2002.

White, R.H. and R.E. Schmidt. 1990. Fall performance and post-dormancy growth of 'Midiron' bemudagrass in response to nitrogen, iron, and benzyladenine. J. Amer. Soc. Hort. Sci. 155: 57-61.

Youngner, V.B. 1959. Growth of U-3 bermudagrass under various day and night temperatures and light intensities. Agron. J. 55:557-559. 